\title{
How Surgical Leaders Transform Their Residents to Craft Their Jobs: Surgeons' Perspective
}

Citation for published version (APA):

Dominguez, L. C., Dolmans, D., Restrepo, J., de Grave, W., Sanabria, A., \& Stassen, L. (2021). How Surgical Leaders Transform Their Residents to Craft Their Jobs: Surgeons' Perspective. Journal of Surgical Research, 265, 233-244. https://doi.org/10.1016/j.jss.2021.03.034

Document status and date:

Published: 01/09/2021

DOI:

10.1016/j.jss.2021.03.034

Document Version:

Publisher's PDF, also known as Version of record

Document license:

Taverne

\section{Please check the document version of this publication:}

- A submitted manuscript is the version of the article upon submission and before peer-review. There can be important differences between the submitted version and the official published version of record.

People interested in the research are advised to contact the author for the final version of the publication, or visit the DOI to the publisher's website.

- The final author version and the galley proof are versions of the publication after peer review.

- The final published version features the final layout of the paper including the volume, issue and page numbers.

Link to publication

\footnotetext{
General rights Owners
rights.

- You may freely distribute the URL identifying the publication in the public portal. please follow below link for the End User Agreement:

www.umlib.nl/taverne-license

Take down policy

If you believe that this document breaches copyright please contact us at:

repository@maastrichtuniversity.nl

providing details and we will investigate your claim.
}

Copyright and moral rights for the publications made accessible in the public portal are retained by the authors and/or other copyright owners and it is a condition of accessing publications that users recognise and abide by the legal requirements associated with these

- Users may download and print one copy of any publication from the public portal for the purpose of private study or research.

- You may not further distribute the material or use it for any profit-making activity or commercial gain

If the publication is distributed under the terms of Article $25 \mathrm{fa}$ of the Dutch Copyright Act, indicated by the "Taverne" license above, 


\title{
How Surgical Leaders Transform Their Residents to Craft Their Jobs: Surgeons' Perspective
}

\author{
Luis Carlos Domínguez, MD PhD, , Diana Dolmans, PhD, ${ }^{b}$ \\ Jorge Restrepo, MD MHPE, ${ }^{c}$ Willem de Grave, $\mathrm{PhD},{ }^{b}$ Alvaro Sanabria, MD \\ $\mathrm{PhD},{ }^{a}$ and Laurents Stassen, MD PhD, ${ }^{d}$ \\ a Department of Surgery, Universidad de la Sabana, Chía, Colombia \\ ${ }^{b}$ Department of Educational Development and Research, School of Health Professions Education, Faculty of Health, \\ Medicine and Life Sciences, Maastricht University, Maastricht, Netherlands \\ ${ }^{\mathrm{c}}$ Department of Medical Education, Universidad de la Sabana, Chía, Colombia \\ d Department of Surgery, Maastricht University Medical Center (MUMC+), Maastricht, Netherlands
}

\section{A R T I C L E I N F O}

Article history:

Received 15 October 2020

Revised 3 March 2021

Accepted 23 March 2021

Available online 3 May 2021

Keywords:

Job crafting

Transformational leadership

Residency training

Workplace-based learning

\begin{abstract}
A B S T R A C T
Background: Surgeons should transform their residents to take the lead in their jobs and optimize their working conditions, so-called job crafting. We investigated the actions undertaken by surgeons with a transformational leadership style to encourage residents' job crafting, about which there is at present a paucity of information.

Methods: We performed a qualitative study based on principles of constructivist grounded theory. In-depth interviews were held with a purposive sample of surgeons who were perceived as transformational leaders by their residents. During data analysis (open, axial, and selective coding), we compared inductive codes with deductive codes drawn from the job demands-resources and transformational leadership theories to reach a consensus on the interpretation of data and identification of the main themes.

Results: Sixteen surgeons participated. Surgeons undertook five actions that enhanced job crafting in residents. They: one) modeled positive behaviors of a good surgeon; two) used a stepwise individual approach toward autonomy; three) connected with the resident as a person; four) supported residents in handling complications and errors; and five) they coached the resident to deal with competing interests. These actions had four consequences for residents. They led to: one) more responsibilities in patient care; two) more constructive relationships in the workplace; three) less pressure from workload and surgical care duties; and four) less personal difficulties and errors in patient care.

Conclusions: The actions undertaken by surgeons with a transformational leadership style have a positive association with the residents' ability to craft their jobs. This knowledge has implications for surgeons' leadership development with a view to workplace education.
\end{abstract}

(c) 2021 Elsevier Inc. All rights reserved.

\footnotetext{
* Corresponding author: Department of Surgery, Faculty of Medicine, Universidad de la Sabana, Campus del Puente del Común, Km 7. Autopista Norte, Chía (Colombia), Tel.: +5 718615555

E-mail address: carlosdot@unisabana.edu.co (L.C. Domínguez). 0022-4804/@ 2021 Elsevier Inc. All rights reserved. 


\section{Introduction}

Surgical residents learn by working in a complex clinical environment. Unfortunately, increasing demands and a lack of resources for workplace-based training have caused rates of burnout among surgical residents to inflate to $58.39 \%$ globally. ${ }^{1}$ By demands, we refer to aspects that cost energy, such as facing obstacles and challenges at work, ${ }^{2,3}$ including workload, pressure, and bullying. ${ }^{4-7}$ Resources, by contrast, refer to aspects that help to decrease such demands and achieve goals at work. ${ }^{2,3}$ Decreased feedback and mentoring, and inappropriate resident autonomy are some examples of poor resources in surgical training. ${ }^{4-7}$ Ultimately, this paucity may result in low performance, depression, or burnout, in turn driving attrition from training programs and suboptimal surgical care. $^{8-11}$

Within the complexity of training, surgeons should, through their leadership, help their residents to strengthen their ability to craft their jobs. Job crafting is about the individual ability to optimize the demands and resources in the workplace. ${ }^{3}$ By doing so, rather than being passive experiencers of the working conditions in which they are immersed, residents can become proactive in shaping their work. Such successful job crafting may eventually promote residents' work engagement - the opposite of burnout ${ }^{12}$ - and their persistence in surgical training. ${ }^{11,13}$

Leadership can be defined as a dynamic process of mutual influences, change, and constant interactions between individuals in a social environment. ${ }^{14}$ In the past decade, a transformational leadership style of surgeons has received increasing attention. ${ }^{15-17}$ Transformational leaders are team-oriented and display behaviors that can be categorized into: i) idealized influence (which they wield, e.g., by means of role modeling); ii) individual consideration (they attend to the needs of others); iii) intellectual stimulation (they foster creativity, innovation, and new ways of thinking in others); and iv) inspirational motivation (they articulate inspiring visions of the future). ${ }^{18,19}$

Job crafting, on the other hand, takes center stage in the job demands-resources (JD-R) theory, a framework for understanding wellbeing (i.e., work engagement) and performance at work. ${ }^{3}$ Within the JD-R theory, job crafting aims to increase: i) structural resources (those related to autonomy); ii) social resources (those associated with relatedness, such as support from peers); and iii) challenging demands (those that promote personal growth and development) at work. At the same time, job crafting aims to diminish hindering demands (those that inhibit the achievement of goals, such as conflicts at work). ${ }^{2}$

According to the transformational leadership and JD-R theories, leaders should stimulate their followers to craft their jobs. ${ }^{12,20}$ However, empirical evidence for this approach is lacking. Further research is therefore needed to understand how surgeons transform their residents to take the lead in crafting their job. Such research can help identify specific areas of surgeons' leadership that require further development to meet the challenges of workplace education. In a more theoretical vein, such research might also offer more insight into how such transformation occurs. ${ }^{20}$ With these aims in mind, we formulated the following research questions (RQs):
RQ1: What actions do surgeons with a transformational leadership style undertake to strengthen their residents' job crafting in training, from surgeons' perspective?

RQ2: What consequences do these actions have for the resident, from surgeons' perspective?

\section{Methods}

\section{Research design}

Our study was directed by principles of constructivist grounded theory (GT), which acknowledges the interpretive nature of knowledge generation, as well as the subjectivity of participants and researchers. ${ }^{21,22}$ Considering its methodological foundations and exploratory approach, the principles of constructivist GT fitted well with our RQs, as it offered an appropriate framework from which to explore the social processes involved in the topic under scrutiny. While we used constructivist GT to guide our study design, we note that our study diverts from classic GT methodology with regard to the role of existing theoretical frameworks: we used two existing theories, the job-demands resources theory and transformational leadership theory, to guide our data collection and analysis, whereas in classic GT researchers commonly approach the research topic more openly. ${ }^{23-25}$ The study was approved in its ethical aspects by the Institutional Review Board of the School of Medicine, Universidad de la Sabana, Colombia (\#41519).

In light of the aforesaid, we note that we, as researchers, were actively involved in developing the theory. In other words, we acknowledge that we are not passive observers of the research field. Our backgrounds, experiences, and conception of the main topic have influenced our interpretations and added meaning to the findings of this study and therefore required reflexivity. LCD, AS, and LS are active surgeons, clinical supervisors, and directors of surgical programs in Colombia and the Netherlands, respectively. JR is a neurologist and director of a masters' program in Health Professions Education in Colombia. Consequently, all of them have an understanding and impression of what constitutes leadership in the workplace and residency training. Finally, DD and WdG are educational scientists and researchers with extensive experience in the field of workplace-based learning in postgraduate medical education.

\section{Setting}

The study was conducted in Colombia, where surgical training is university-based and lasts four years. There are 20 active programs, spanning 400 residency positions per year. Residents do not receive a salary and, as such, they do not enjoy an official employee status in the health institutions in which they serve. Nevertheless, they do have legal responsibilities in patient care and daily clinical duties. In almost $60 \%$ of the programs, residents must pay an annual tuition fee of approximately 12,000 USD. The burnout rate in surgical residents is $33.1 \% .{ }^{11}$ 


\section{Participants}

We used a purposive sampling approach focused on identifying participants that could provide rich and relevant data in light of our theoretical purpose, as is common in GT. ${ }^{23,24} \mathrm{We}$ operationalized this sampling approach by recruiting 16 surgeons who were clear exponents of a transformational leadership style. In a previous study, we had requested residents from seven surgical programs to rate the leadership style of the surgeons in charge of their clinical supervision, using the Multifactor Leadership Questionnaire. ${ }^{26}$ By aggregating their evaluations, we obtained a composite score for each of the three leadership styles present in each program: transformational, transactional, and laissez-faire leadership. Based on this information, we were able to determine in which programs a transformational leadership style prevailed, which was the case when the following two criteria were met: 1) the program was given a score of $>3.5$ for a transformational leadership style (range 1-5) and; 2) the score for a transformational leadership style was higher than the scores for the other (transactional and laissez-faire) styles. Four programs fulfilled these criteria. However, we expected that not all surgeons of these programs would necessarily be exponents of such a transformational leadership style. LCD and AS therefore enlisted the help of the directors and chief residents of each program to recruit surgeons who were obvious exponents of this style, after having explained to them the main characteristics that go with it. A total of 16 surgeons were identified and invited to participate in individual, in-depth interviews. Considering that all surgeons with a transformational leadership style in our research setting agreed to participate, our potential sample was exhausted and, in contrast to what is common in GT, we did not recruit more participants iteratively.

\section{Data collection}

From September to December, 2019, LCD and JR conducted individual semi-structured interviews in Spanish language (face to face or via telephone) based on a preliminary interview guide to create a safe atmosphere for the interviewees (Appendix A). The interview guide was devised from the jobcrafting concepts in the JD-R theory (i.e., to increase structural resources and to diminish hindering demands). ${ }^{2,3}$ The purpose and scope of the study were explained to the participants as well as the mechanisms to ensure anonymity, confidentiality, and the further management of information. Prior to participation, all surgeons gave their written or verbal consent. Each interview was audiotaped, transcribed verbatim, and pseudonymized immediately upon completion. In successive meetings, LCD and JR discussed the general impressions they had formed during data collection.

\section{Data analysis}

Data analysis was highly dynamic, as inductive and deductive coding overlapped recurrently throughout the whole process. First, LCD, JR, and AS independently read the verbatim transcripts. In an iterative process, they consequently identified general ideas that guided further data collection in subsequent interviews. These ideas were grouped into small units
Table 1 - Characteristics of the study population

\begin{tabular}{|c|c|}
\hline Characteristics & Study sample \\
\hline Surgeons, $n$ & 16 \\
\hline Male surgeons, $n(\%)$ & $14(87.5 \%)$ \\
\hline Female surgeons, $n(\%)$ & $2(12.5 \%)$ \\
\hline Age of participants (mean, SD, range) & $47.18 ; 7.95 ; 32-65$ \\
\hline \multicolumn{2}{|c|}{ Years of surgeons' experience as supervisors (mebz $56 \mathrm{D}, \mathrm{m}, \mathrm{ge}) 30$} \\
\hline Interviews conducted in person, $n(\%)$ & $12(75 \%)$ \\
\hline Interviews conducted via telephone, $n(\%)$ & $4(25 \%)$ \\
\hline Duration of interviews, mean (range) & $51.48 \min (38-65)$ \\
\hline Number of training programs, $n$ & 4 \\
\hline \multicolumn{2}{|l|}{ Number of surgeons per program, $n(\%)$} \\
\hline Program 1 & $5(31.25 \%)$ \\
\hline Program 2 & $5(31.25 \%)$ \\
\hline Program 3 & $4(25 \%)$ \\
\hline Program 4 & $2(12.5 \%)$ \\
\hline
\end{tabular}

of analysis, which, in turn, were grouped into related categories, and categories into general themes.

As inductive coding progressed, LCD, AS, and JR reflected on the role of several sensitizing concepts (i.e., aspects that we a priori expected to identify in the analysis based on the transformational leadership and JD-R theories). ${ }^{3,27}$ We derived several codes from these theories, such as those relating to jobcrafting behaviors (e.g., to increase structural resources) and to a transformational leadership style (e.g., intellectual stimulation). This combination of inductive and deductive coding ultimately helped us to understand participants' perspective on a more theoretical level and to construct our final themes. The resulting themes were discussed with all authors (DD, LPS, WdG) until we reached consensus.

In all stages of analysis (open coding, axial coding, and selective coding), constant comparison of inductive and deductive codes enabled us to develop a theory with interpretive meaning and not just a description of themes. ${ }^{28}$ In this study we identified, recruited and interviewed sixteen surgeons with a transformational leadership style. We reached theoretical sufficiency, which is defined as no emergence of new themes, ${ }^{29}$ after fourteen interviews, but nevertheless decided to interview them all given they were identified and recruited beforehand.

Finally, we validated our findings by comparing these with the existing literature. In all stages of the qualitative phase, we followed standard recommendations for the translation of information, in our case from Spanish into English language. $^{30,31}$ Similarly, we adopted a framework of consolidated criteria to report our qualitative results. ${ }^{32}$

\section{Results}

All 16 surgeons agreed to participate. Characteristics of the study population are presented in Table 1 . From the analysis, we were able to construct five themes that corresponded to surgeons' actions mentioned in RQ1 (Table 2 gives an overview 
Table 2 - Representative quotations on the actions undertake by surgeons with a transformational leadership style to strengthen residents' job crafting

Theme 1: Modelling positive behaviours of a good surgeon

Scope of modelling "An average surgeon is someone who just operates ... An academic surgeon is a leader who sets an example ... making people believe and follow and improve ... If you do not surprise the resident with your positive role model and leadership, they will not have good clinical or academic results ... This is what sets him/her apart from the one who just operates, from the regular surgeon." (Surgeon\#10)

Modelling professionalism in

"I comply with my surgical duties. I know everything about my patient and the result of his/her patient care diagnostic tests. I know their surgical pathology very well ... I am punctual in my duties ... I want that he/she [the resident] sees that I am active with my patient ... They have to realize what I am doing for the patient. So, I stimulate them to care about the patient." (Surgeon\#5)

Modelling appropriate relationships at the workplace

"I put great emphasis on good interpersonal relationships ... on treating others well .... I cannot demand that residents behave well when I behave badly. It is important that they understand that most things can be achieved through good relationships." (Surgeon\#6)

Modelling coherence between personal and professional life

"I try to share my experiences with literature, arts, music, and cinema. I want them to realize how these experiences are related to surgery. It also seems very important to me to tell them about my life, my experiences of when I was a resident, when I was a rural surgeon, or when I was at war .... Life goes by too quickly to be only in a hospital or an operating room." (Surgeon\#16)

Having a clear vision of surgical education

"The surgeon was an alpha male ... a pernicious leader, bully, abuser, and a person who did not dialog .... But, that's how surgeons used to be. Nowadays, leadership has changed a lot. It is about getting something done with the team [the patient, a project, a research study] .... This requires good examples .... In the future, I hope that the supervisors of the new generations will have a different vision of what education really is .... Dinosaurs are going to become extinct at some point." (Surgeon\#7)

Theme 2: Using a stepwise individual approach toward autonomy

Identifying prior expertise and residents' capabilities

"First, you must know the experience of the resident ... then, we should explain to him/her what the job is, what the specific objectives of the current rotation are, as well as the way in which we work .... Thus, a model of specific supervision is built for each resident." (Surgeon\#16)

Delivering progressive autonomy avoiding abrupt changes of responsibility

"I use a sequence of steps .... First, the resident enters surgery and I explain to him/her the steps of the operative procedure. Then, he/she enters several times as an assistant .... After a certain number of procedures, I evaluate whether he/she has the competency to start performing parts of the procedure. So, I allow him/her to carry out some specific steps .... Later, when he/she is more autonomous, I allow him/her to carry out the entire procedure and I just help .... Finally, there is a moment in which I do not participate, physically, in the procedure. The resident completes the procedure alone, but I am available to assist him/her." (Surgeon\#7)

Theme 3: Connecting with the resident as a person

Showing genuine interest in residents' life

"I believe that it is very important to know the resident as a person. It is important for teaching ... I believe in education from the person. As a surgeon and supervisor, that demands more of me. That goes beyond training him/her to make surgical stitches." (Surgeon\#1).

Supporting expectations and residents' interests

"There are "carnivorous" and "herbivorous" surgeons .... I think we need surgeons in many positions. Not everyone is going to be a head transplant surgeon ["carnivore"]. We need surgeons in the emergency room, in the intensive care unit, others should lead nutritional support teams, and [yet] others should be epidemiologists or MBAs ["herbivores"] .... We must help the resident to identify their strengths ... one size does not fit all .... It is important that those who are "herbivorous" meet the minimum skills and requirements to be certified as surgeons. But we have to support their initiatives ... those things that are really fascinating for them." (Surgeon\#3)

Being aware of residents' emotional distress

Promoting residents' resilience
"It is important to know the residents in order to detect their emotional, psychological, or depression problems, and help them .... Surgeons should be sensitized to these human needs residents have." (Surgeon\#15)

"Resilience is very important for the resident. Not "resistant" resilience but "reflective" resilience. Through reflective resilience a person can understand their frustrations and difficulties, reflect on them and take actions ... daily conversations with residents about this are very important." (Surgeon\#1). 
Table 2 - (continued)

Theme 4: Supporting the resident

in handling complications and errors

Reflecting on the boundaries of surgical profession

"We have always been trained with high self-criticism and self-blame. Many errors, however, are not our fault, but they are very frustrating .... For example, when a resident "fails" to save the life of a traumatized patient, he/she feels guilt and seeks explanations in medical errors or in controversial decisions." (Surgeon\#9).

Giving private feedback

"One should definitely exalt the good things publicly and correct privately .... One should not take the resident to the morbidity and mortality meeting to crucify him/her .... When one punishes him/her publicly, the resident will depart from his/her learning curve. If he/she is underperforming, their performance will become worse. If they avoid complex cases, then he/she will avoid more cases to prevent punishment. They will look for excuses ...." (Surgeon\#10)

Giving opportunities of participation to solve complications, avoiding blame.
"First of all, I am in charge of the patient. So, residents' complications are my complications .... If I allowed the resident to participate in the surgical treatment of the patient and something went wrong, it is not just their fault ... he/she is in a learning process. This is why I accept the complications, but I ask [the resident]: "what did we do, what should we have done, and what should we do [now]?". (Surgeon\#6)

\section{Theme 5: Coaching the resident to} deal with competing interest

Promoting residents' awareness on the importance of administrative duties for patient care

"There is a persistent criticism that the system is wrong... many forms should be filled [out]. People [surgeons and residents] always have complaints, but for the proper functioning of the institution there must be economic profit. The provision of health service is not an act of charity .... Residents must be aware of these aspects .... Anything that is requested [for example, devices, sutures] can be used with the correct indication and relevance. This involves administrative work that must be done so that the institution does not lose money .... You must be an ally of your institution. The institution and the third payer are not your enemies ... this is as important as operating well [surgical procedures]." (Surgeon\#3)

Relieving residents' pressure and workload.

Coaching on prioritization of tasks
"I help them with the workload [clinical and administrative] ... working with four hands is more efficient .... I also do it because it is my responsibility. I am the surgeon in charge; residents are in training. When they are working, they are helping me to relieve my workload .... I should be grateful to them." (Surgeon\#8)

"Residents must identify what is most important to do and organize their work .... I insist that they prioritize tasks. For example, we always start the surgical round by visiting critical patients, we define the most important tasks for those patients and the order in which we will carry them out." (Surgeon\#12)

Coaching on effective delegation
"It is vital that residents learn to delegate to others [e.g., junior residents, interns, students] to reduce the number of activities that overload and blur what needs to be done. This implies learning to work as a team. Overloading is one of residents' problems because they want to do everything by themselves." (Surgeon\#10). of representative quotations), and four themes representing the consequences of these actions for residents, addressing RQ2 (Table 3 gives an overview of representative quotations). Fig. 1 gives an overview of the main findings.

What actions do surgeons with a transformational leadership style undertake to strengthen residents' job crafting?

Theme 1. Modeling positive behaviors of a good surgeon

Surgeons appreciated the importance of demonstrating correct professional behaviors that residents could identify and emulate. Such role modeling went beyond the manual dexterity to execute surgical operations. Surgeons also had a clear vision of what they expected of residents during patient care, of their relationships with other surgeons and team members, and of the balance between personal and professional life. Interestingly, they had long-term views of surgical education in which tomorrow's supervisors were today's residents.
Theme 2. Using a stepwise individual approach toward autonomy

For surgeons, residents' involvement in surgical care required a gradual transformation of their autonomy in the operating room and other clinical settings. However, surgeons emphasized that the speed and scope of such transformation should be based on individual plans of training fitted to the resident's personal needs, his/her prior expertise, and level of intended outcomes of training. Such approach to autonomy aimed to improve residents' performance, while avoiding abrupt changes in responsibilities during training.

\section{Theme 3. Connecting with the resident as a person}

The surgeons in our study did not perceive residents as just workers, but as individuals with a personal and family life. They were looking for cues that allowed them to strengthen their interpersonal relationships with residents and identify interests and expectations that could foster their personal development. In this connection, it was also important to iden- 
Table 3 - Representative quotations on the main consequences for the resident, resulting from the actions of surgeons with a transformational leadership style

\begin{tabular}{|c|c|}
\hline $\begin{array}{l}\text { Residents' role as a surgeon in } \\
\text { training }\end{array}$ & $\begin{array}{l}\text { "They [residents come to appreciate the importance of what they are doing [when they see } \\
\text { professionalism in patient care in the supervisor] ... they assume the role of a surgeon in training } \\
\text { with responsibility." (Surgeon\#9)] }\end{array}$ \\
\hline $\begin{array}{l}\text { Residents' competence / } \\
\text { self-confidence }\end{array}$ & $\begin{array}{l}\text { "I believe that [one of the] consequences is generating skills in the resident to operate [on] a patient, } \\
\text { independently, in the future. They gain self-confidence." (Surgeon\#7) }\end{array}$ \\
\hline Residents' compassion & $\begin{array}{l}\text { "I notice that residents take more care of the patient [when they are supported by the supervisor, as } \\
\text { specified under Theme 4]. They are committed and interested .... It makes residents value their } \\
\text { patient, and the patient is not just another number." (Surgeon\#4) }\end{array}$ \\
\hline Residents' initiative & $\begin{array}{l}\text { "The one who takes risks has a greater chance of failure ... but if I fail and am punished for that, then } \\
\text { I will not take more risks .... When that vicious circle, based on fear and punishment, is broken ... } \\
\text { the person can assume new challenges ... Residents are not going to evade their responsibilities." } \\
\text { (Surgeon\#7) }\end{array}$ \\
\hline
\end{tabular}

Residents develop more constructive relationships in the workplace

Residents' communication / interactions in the workplace

"I feel that the residents improve their communication, and they are kind to each other [when they identify positive behaviors in their supervisors and try to emulate these]. Their interactions improve ... the consequences are evident. In general, one sees that the resident who was uncompromising and had interpersonal problems changes positively." (Surgeon\#16)

Resident's leadership

"One realizes that they [residents] have more 'voice of command,' more leadership [when they identify positive behaviors in their supervisors and try to emulate these]. They begin to teach other residents." (Surgeon\#13).

Residents experience less pressure
from workload and surgical care
duties

Residents' stress

Residents' decision making

Residents' look for new challenges

Residents' work-recovery
"When residents use these strategies [i.e., prioritization, delegation], I observe that they are calmer, they look less distressed. The environment has improved because of reduced pressure." (Surgeon\#7)

"It [prioritization and delegation] allows the resident to take the time for making better decisions ... not acting in a hurry, but thinking." (Surgeon\#2)

"They organize and plan their work better [when delegating effectively] .... They save time ... this allows them to look for opportunities. For example, to operate [on] a patient with a critical condition in the midst of a heavy clinical workload." (Surgeon\#12).

"To learn surgery, you need a lot of hours under the lamp, in the OR, and in the hospital. But free time is also important ... time with family and time to rest .... They [residents] value free time [when supervisors respect their work schedules]. They are grateful because it allows them to recharge their batteries. That motivates them." (Surgeon\#9).

\section{Residents experience less tension from personal difficulties and errors in patient care}

Residents' afraid / interaction with the supervisor

Residents' resilience
"Residents become very calm ... they create bonds [when they discuss their personal problems with the supervisor]. The resident, in turn, feels less pressured, less observed, less watched. Feeling closely observed is negative for the resident .... Bonds make them open up their own lives ... it is a valve of emotional relief for residents. So, we can help them." (Surgeon\#9)

"They recover quickly [from complications], when reflecting on these aspects, when analyzing the case taking into account the context and the available evidence." (Surgeon\#9) tify potential sources of emotional distress in the resident, to be able to advise about personal difficulties, and to promote resiliency in training. This, however, required authenticity and openness.

Theme 4. Supporting the resident in handling complications and errors

According to surgeons, residents frequently blamed themselves for making errors and causing complications. Their support helped residents to cope with such adverse situa- tions and to understand the risks of surgery and the boundaries of the surgical profession. Moreover, surgeons acknowledged that good support required them to give private feedback, preventing the resident from being humiliated in public when complications arose, especially in surgical meetings. They acknowledged that constructive environments that allowed for open discussion contributed positively to residents' learning from complications. Ultimately, surgeons recognized that a surgical educator should offer residents the opportunity to handle complications. Rather than blaming and aban- 


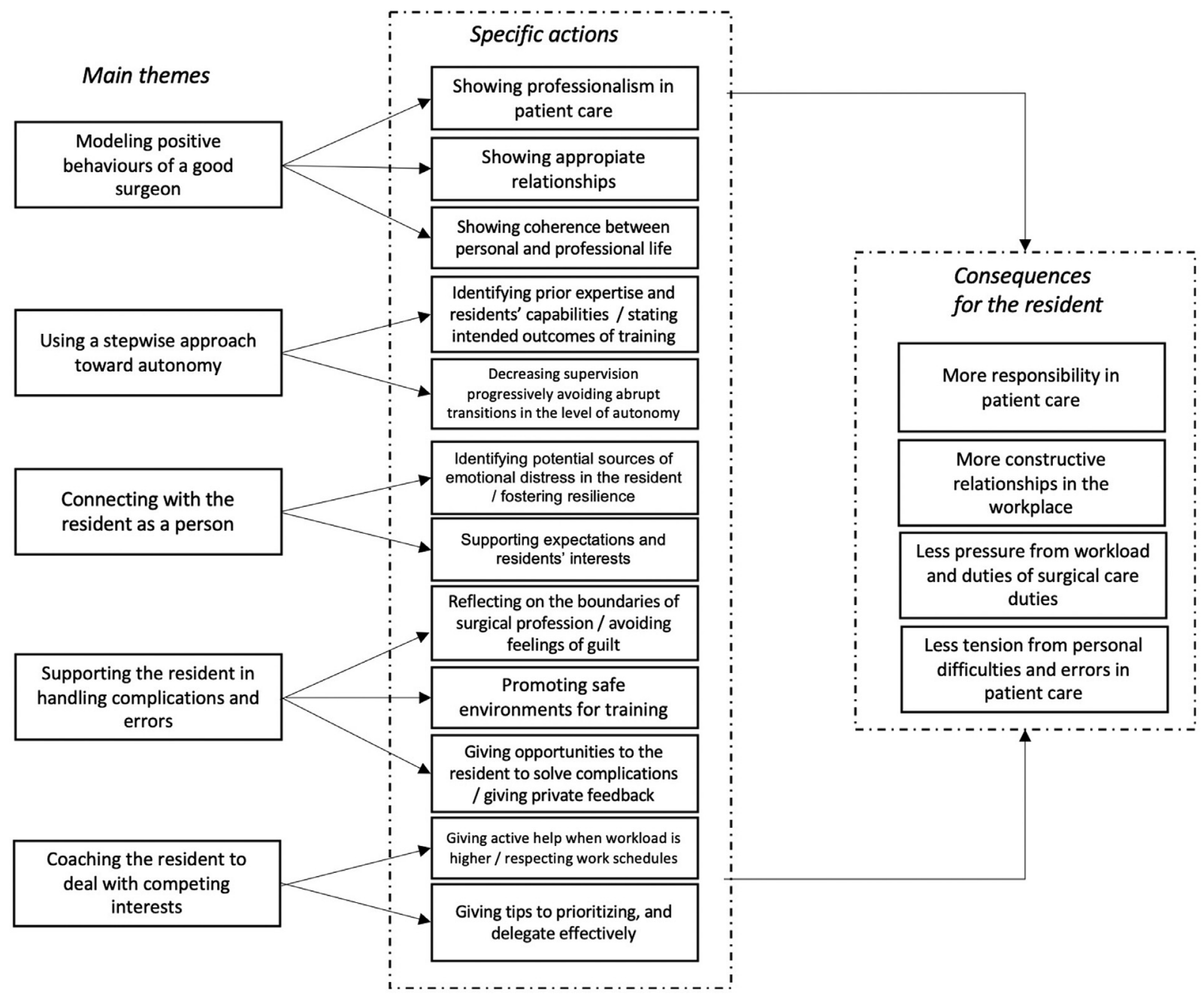

Fig. 1 - Conceptual model of the actions undertaken by supervisors who are exponents of a transformational leadership style and of the consequences for the surgical resident.

doning the resident when complications arose, they involved the resident in solving complications during the whole continuum of patient care.

Theme 5. Coaching the resident to deal with competing interests

Participants were aware that residents were exposed to a heavy workload, long work shifts, and administrative pressure. Yet, they still appreciated the rationale behind this amount of administrative load in contemporary surgical care and the importance of making residents aware of this. However, these challenges also called for specific actions on their part. More specifically, to relieve pressure, surgeons made sure not to transfer all workload to residents, to assist them when their load was too high, and to respect their work schedules. In addition to this, surgeons provided the resident with tips on how to handle the workload. These tips focused on the identification of care priorities (e.g., in the case of patients with lifethreatening conditions) and on the delegation of tasks (based on the task itself, clinical status of patients, and the expertise of other team members).

What consequences do surgeons believe their actions will have for residents?

\section{Residents take on more responsibilities in patient care}

Surgeons perceived that their modeling behaviors (Theme 1) encouraged residents to assume more responsibilities in patient care based on sound judgment and integrity. For instance, they observed that residents more readily assumed the role of surgeon in training, taking surgical decisions with more confidence and prudence. Similarly, surgeons believed that an individual approach toward autonomy (Theme 2) promoted the competence and responsibility in residents to independently bring surgical operations to a successful completion. Finally, surgeons noted that their support to residents in dealing with errors (Theme 4) promoted courage and initiative in the resident to overcome complications satisfactorily, to stay compassionate, and to take on responsibilities in subsequent cases.

\section{Residents develop more constructive relationships in the workplace}

Many surgeons noted that modeling (Theme 1) was important for residents to strengthen their interpersonal relationships 
with peers, supervisors, and nurses, and to befriend others. Supervisors observed more collaboration between residents and better communication, as well as more abilities to solve work conflicts satisfactorily with emotional intelligence and kindness. Similarly, they noted that residents were more inclined to lead and teach others, such as junior residents or medical students.

\section{Residents experience less pressure from workload and surgical care duties}

Surgeons noted that coaching residents to prioritize and delegate (Theme 5) helped them to better plan their tasks, improve their decision-making capacity, and seek opportunities at work (for instance, to perform surgical operations of interest to them). Similarly, surgeons perceived that respecting residents' work schedules (Theme 5) and modeling satisfactory relationships to improve collaboration (Theme 1) were important to relieve residents' workload, thereby minimizing exhaustion. As a result, residents had more free time after work to recover from the surgical environment.

\section{Residents experience less tension from personal difficulties and errors in patient care}

By connecting with residents (Theme 3), surgeons believed they helped them to find effective ways to solve their personal problems and to advance in their interests (for instance, by improving aspects of their professional development). Likewise, surgeons' support (as mentioned under Theme 4) caused residents to be less afraid of being punished when complications arose, while cultivating their resilience and freeing learning opportunities. Surgeons also allude to residents' gratitude when supervisors truly listen to them and to the positive impact such relationships have on their work. Finally, supervisors believed that residents really appreciated their encouragement to reflect on the limits of the surgical profession so as to overcome adverse events during training. They perceived less anxiety in residents.

\section{Discussion}

Our qualitative survey has provided empirical evidence of how surgeons with a transformational leadership style can foster residents' job crafting. The results suggest that these surgeons influence and motivate their residents by means of role modeling, by individualizing and considering residents' needs, and by stimulating them intellectually to develop new ways of thinking. In surgeons' view, these actions foster residents' ability to take control of their job and increase responsibility and autonomy, strengthen their social relationships, and reduce pressure and tensions in the workplace.

The said actions undertaken by the surgeons in this study, addressing our first research question, tie in nicely with the main characteristics of a leader as described in transformational leadership theory. ${ }^{20,27}$ For instance, surgeons' efforts to model professionalism and satisfactory relationships with others in the workplace, and their approach to strengthening residents' autonomy (Themes 1-2) closely resemble the theory's pillars of "idealized influence" and "inspirational motivation." Similarly, surgeons exhibited "individual consideration" by connecting with and supporting residents (Themes 34) as well as "intellectual stimulation" by challenging them to find satisfactory solutions to complications and competing interests (Themes 4-5). These actions reveal that surgeons with a transformational leadership style prioritize having "human relationships" with their residents over the actual "task," an observation that is common in transformational leadership research. ${ }^{33,34}$

These findings are also consistent with those of earlier studies. A preliminary mixed-methods study into residents' perspective in surgical training, for instance, revealed that surgeons' transformational leadership style had a positive effect on residents' job crafting. ${ }^{26}$ More specifically, surgeons who were exponents of that style created a constructive atmosphere for training, provided the resident with more resources (in the form of teaching and feedback), and modeled effective ways to handle the demands in the workplace. ${ }^{26}$ Similar findings were identified in non-surgical settings. ${ }^{35,36}$

To address research question two, surgeons' actions also had consequences for residents, which appeared to be in perfect harmony with the job-crafting concept. Our analysis revealed that surgeons encouraged their residents to take the lead and craft their jobs by emphasizing their personal strengths, which they considered "constant near perfect performance[s]" shaped by talent, knowledge, and skills. ${ }^{37}$ This mechanism deserves more empirical underpinning in transformational leadership theory. ${ }^{20}$ Our findings moreover indicated that by modeling professionalism in patient care, surgeons also fostered other specific strengths in the resident, such as judgment and integrity. Residents need such strengths to enhance structural resources, such as autonomy and responsibility in the workplace, and take on new challenges (first consequence). Similarly, we found that by modeling satisfactory relationships with others, surgeons stimulated emotional intelligence and kindness in the resident, strengths that are needed to enhance social resources, such as peer collaboration and feedback (second consequence). This finding is consistent with previous studies in surgical training. ${ }^{38-40} \mathrm{Fi}-$ nally, by supporting and connecting with the resident, surgeons promoted courage and resilience, which are important qualities to help reduce hindering demands, such as pressure and tensions in the workplace (third and fourth consequences). This finding resonates with previous studies on the role of resilience in surgical training. ${ }^{41,42}$

Our study contributes to the existing literature and theory in different ways. First, compared to previous studies, it goes one step further by exploring how leaders can transform their followers to take the lead in crafting their job. While previous studies took either a transformational leadership theory or job-crafting perspective, we have combined the two. Second, as most research on leadership and job crafting has been conducted in non-educational contexts, our study is among the few to bring workplace education into sharper focus. Moreover, previous research predominantly made use of surveys; ${ }^{35,36,43-47}$ our qualitative approach, however, allowed for a better understanding of how surgeons can transform residents to shape or craft their own job. In this way, we were 
able to contribute to the body of leadership and job-crafting research in the context of postgraduate medical education, responding to the need to explain how and why leadership occurs in specific social contexts. ${ }^{14}$ We concluded that surgical leaders can transform to their residents to craft their job by means of role modeling or by idealizing their influence, attending to their needs, and by stimulating them intellectually to develop new ways of thinking. In doing so, they help residents to shape their job by reducing pressure and tensions in the workplace and by encouraging them to strengthen their social relationships. Our findings help us to delineate the specific attributes of a modern surgical leader described in previous studies, with a focus on education in the workplace. ${ }^{48-50}$

Besides strengths this study also has limitations. A first limitation is that our study was conducted in one specific setting, namely Colombia, which might limit the generalizability of our findings. Nevertheless, we do find it plausible that most of the themes and consequences discussed are transferable to other countries, because the surgical training model shares similar features across countries, especially in the West, including a hierarchical structure, competition, and pressure on residents to meet high standards. ${ }^{51-54}$ A second limitation is that the number of female participants was low $(12.5 \%$ of the sample). This can be explained, in part, by the fact that the proportion of women among faculty in general is still small, despite the significant increase in female surgeons in Colombia. Yet, we argue that there is no reason to assume that our findings would reveal major differences in terms of the actions of transformational leaders and their respective consequences for residents, had more female surgeons been included. A final limitation is that we did not directly observe surgeons' leadership and residents' job crafting behaviors in their real workplace training environment.

We strongly believe that the key features of surgical leadership identified in this study have implications for practice. More specifically, they can help surgeons to self-reflect on their leadership behaviors and raise awareness of what specific actions they can undertake to guide their residents in optimizing job demands and resources in the workplace. In the complex dynamics of the social training environment, surgical leaders must make sure their educational actions are aimed at raising situational awareness among residents. The results of the present study can serve faculty training purposes with a view to coaching, developing, and guiding residents in the workplace. If training is based on the situated actions identified in this study, its intended outcomes may help reduce the ambiguity of leadership in surgeons' daily educational practice.

As for future research, we invite researchers to explore our findings in other countries to enhance their generalizability. Further studies are important because surgical education is undergoing a rapid transformation from hierarchical training models to competency-based medical education. ${ }^{51-53,55}$ This development calls for more research into the implications of residents' job crafting for supervisors' entrustment decisions in the workplace. Also, a lack of knowledge about a transformational leadership style in women surgeons offers an opportunity for further exploration with a view to residents' development. Finally, we welcome future research into the interactions between leadership and residents' job crafting in the workplace for training based on direct observations and ethnographic perspectives.

To recap, by focusing on the interactions between surgeons and residents in the workplace-based learning setting, this study has provided evidence for the relevance of transformational leadership in surgical education. Our findings have highlighted the positive association that such leadership of surgeon educators has on residents' job crafting in terms of dealing effectively with job demands and resources during training. These observations have practical implications and they offer a window of opportunity for future research.

\section{Conflict of Interest}

There are no personal conflicts of interest or financial conflicts of interest of any of the authors. All authors have seen and approved the final version of the manuscript being submitted and that all authors fulfill the COPE (Committee on Publication Ethics) requirements for authorship.

\section{Acknowledgements}

We would like to thank to all the surgeons that kindly accepted to participate in this study, to Janneke Frambach (School of Health Professions Education, Maastricht University) for her critical review to the manuscript, and to Angelique van den Heuvel for the English language edition to the manuscript.

The funding of the present research was provided by Universidad de la Sabana (Colombia). The study is part of the $\mathrm{PhD}$ training of Luis Carlos Dominguez (corresponding author) in the School of Health Professions Education (SHE) in Maastricht University (the Netherlands).

\section{Appendix A. Interview guide}

\section{Introductory phase}

- Welcome the participants and thank them for attending

- Introduce the broad research terms

- Explain how the information will be used. Clarify that information will not be used for any purpose other than research and that participants will never be identified personally. Outline of confidential data use and storage

- Audio recording: Inform the interviewee of recording and ask for approval

- Disclosure of ethical issues: Consent for participation (signature of informed consent)

- Respond to inquiries

Introductory vignette: During this conversation we would like to hear what you do in this department to stimulate different abilities in the surgical resident to help them effectively manage their work environment for training.

Ice-breaking question

What do you or does your department do to stimulate the resident to take the lead in his/her development/training in the workplace? 


\section{Key questions}

1. What do you do to encourage residents to gain autonomy and responsibility in their daily work?

2. What do you do to encourage residents to establish satisfactory interactions and collaboration with others in the workplace?

3. What do you do to encourage residents to see errors and frustrations in their daily work as learning opportunities?

4. What do you do to encourage residents to find a suitable work-life equilibrium?

5. What do you do to encourage residents to deal with the demands of training in their daily work, such as role conflicts and workload?

6. What do you do to encourage residents to find new challenges in their work?

\section{Wrap-up question}

1. Would you like to add anything to what we have discussed so far?

2. Authors' contributions:

3. L.C.D. was responsible for the conception of the study, collection and analysis of data, funding acquisition, investigation, methodology, project administration, writing of the original manuscript, and for the revision and editing of the final version.

4. D.D. contributed to the conception of the study, analysis of data, investigation, supervision, methodology, writing of the original manuscript, and to the revision and editing of the final version.

5. J.R. contributed to the collection and analysis of data, investigation, methodology, writing of the original manuscript, and to the revision and editing of the final version.

6. W.d.G. contributed to the conception of the study, analysis of data, investigation, methodology, supervision, writing of the original manuscript, and to the revision and editing of the final version.

7. L.S. contributed to the conception of the study, analysis of data, investigation, methodology, supervision, writing of the original manuscript, and to the revision and editing of the final version.

8. A.S. contributed to the conception of the study, collection and analysis of data, investigation, methodology, supervision, writing of the original manuscript, and to the revision and editing of the final version.

\section{REFERENCES}

1. Low ZX, Yeo KA, Sharma VK, Leung GK, McIntyre RS, Guerrero A, et al. Prevalence of burnout in medical and surgical residents: A meta-analysis. Int J Environ Res Public Health [Internet]. 2019;16:1479. Apr 26 [cited 2019 Sep 30]Available from. http://www.ncbi.nlm.nih.gov/pubmed/31027333

2. Tims M, Bakker A, Derks D. Development and validation of the job crafting scale. J Vocat Behav [Internet]. 2012;80:173-186. [cited 2018 Sep 6]Available from. https://www.sciencedirect. com/science/article/abs/pii/S0001879111000789 .
3. Bakker AB, Demerouti E. Multiple levels in job demands-resources theory: implications for employee well-being and performance. In: Diener E, Oishi S, Tay L, eds. Handbook of wellbeing. Salt Lake City UT: DEF Publishers. DOI:nobascholar.com: DEF Publishers. DOI:nobascholar.com; 2018:1-13.

4. Chiapponi C, Meyer CY, Heinemann S, Meyer F, Biberthaler P, Bruns CJ, et al. Stress-related job analysis for medical students on surgical wards in Germany. J Surg Educ [Internet]. 2017;74:145-153. Jan [cited 2019 Sep 4]Available from. http://www.ncbi.nlm.nih.gov/pubmed/27468974 .

5. Ebrahimi S, Kargar Z. Occupational stress among medical residents in educational hospitals. Ann Occup Environ Med [Internet]. 2018;30:51. [cited 2019 Sep 4]Available from. http://www.ncbi.nlm.nih.gov/pubmed/30101032

6. Huang Y, Chua TC, Saw RPM, Young CJ. Discrimination, bullying and harassment in surgery: A systematic review and meta-analysis. World J Surg [Internet]. 2018;42:3867-3873. [cited 2019 Sep 4]Available from.

http://link.springer.com/10.1007/s00268-018-4716-5

7. Halim UA, Riding DM. Systematic review of the prevalence, impact and mitigating strategies for bullying, undermining behaviour and harassment in the surgical workplace. Br J Surg [Internet]. 2018;105:1390-1397. Oct [cited 2019 Sep 4]Available from. http://www.ncbi.nlm.nih.gov/pubmed/30007001

8. Dimou FM, Eckelbarger D, Riall TS. Surgeon burnout: A systematic review. J Am Coll Surg [Internet]. 2016;222:1230-1239. [cited 2019 Sep 4]Available from. http://www.ncbi.nlm.nih.gov/pubmed/27106639

9. Siegel TR, Nagengast AK. Mitigating Burnout. Surg Clin North Am [Internet]. 2019;99:1029-1035. [cited 2019 Sep 4]Available from. http://www.ncbi.nlm.nih.gov/pubmed/31446908

10. Smeds MR, Janko MR, Allen S, Amankwah K, Arnell T, Ansari $\mathrm{P}$, et al. Burnout and its relationship with perceived stress, self-efficacy, depression, social support, and programmatic factors in general surgery residents. Am J Surg [Internet]. 2019. [cited 2019 Aug 30]Available from. http://www.ncbi.nlm.nih.gov/pubmed/31307660 .

11. Dominguez LC, Stassen L, de Grave W, Sanabria A, Alfonso E, Dolmans D. Taking control: Is job crafting related to the intention to leave surgical training? PLoS One [Internet]. 2019;13. [cited 2020 Sep 27]Available from. https://pubmed.ncbi.nlm.nih.gov/29856750/ .

12. Bakker AB. Strategic and proactive approaches to work engagement. Vol. 46. Organizational Dynamics; 2017.

13. Dominguez LC, Dolmans D, de Grave W, Sanabria A, Stassen LP. Job Crafting to persist in surgical training: A qualitative study from the resident's perspective. J Surg Res [Internet]. 2019;239:180-190. [cited 2019 Mar 29]Available from. http://www.ncbi.nlm.nih.gov/pubmed/30844632.

14. Winkler I. Characteristics of contemporary theoretical approaches in leadership research. Contributions to Management Science Springer; 2009:5-7.

15. Hu YY, Parker SH, Lipsitz SR, Arriaga AF, Peyre SE, Corso KA, et al. Surgeons' leadership styles and team behavior in the operating room. J Am Coll Surg [Internet]. 2016;222:41-51. [cited 2018 Sep 22]Available from. https: //linkinghub.elsevier.com/retrieve/pii/S1072751515016191.

16. Horwitz IB, Horwitz SK, Daram P, Brandt ML, Brunicardi FC, Awad SS. Transformational, transactional, and passive-avoidant leadership characteristics of a surgical resident cohort: analysis using the multifactor leadership questionnaire and implications for improving surgical education curriculums. J Surg Res [Internet]. 2008;148:49-59. [cited 2018 Sep 22]Available from. http: //linkinghub.elsevier.com/retrieve/pii/S0022480408001911.

17. Barling J, Akers A, Beiko D. The impact of positive and negative intraoperative surgeons' leadership behaviors on 
surgical team performance. Am J Surg [Internet]. 2018;215:14-18. [cited 2020 Apr 20]Available from. http://www.ncbi.nlm.nih.gov/pubmed/28754536 .

18. Avolio BJ. Full Range Leadership Development. Second Edi. United States of America SAGE Publications; 2013:280.

19. Lord RG, Day DV, Zaccaro SJ, Avolio BJ, Eagly AH. Leadership in applied psychology: Three waves of theory and research. J Appl Psychol [Internet]. 2017;102:434-451. [cited 2018 Sep 6]Available from. http://www.ncbi.nlm.nih.gov/pubmed/28125257

20. Siangchokyoo N, Klinger RL, Campion ED Follower transformation as the linchpin of transformational leadership theory. 31. A systematic review and future research agenda. Leadersh Q; 2020.

21. Charmaz K. Constructing Grounded Theory. Second Edi. London, UK: SAGE Publications Ltd; 2014416 p.

22. Konkin J, Suddards C, Konkin J, Suddards C. Creating stories to live by: caring and professional identity formation in a longitudinal integrated clerkship. Adv Heal Sci Educ. 2012;17:585-596.

23. Watling CJ, Lingard L. Grounded theory in medical education research: AMEE Guide No. 70. Med Teach. 2012;34:850-861.

24. Hennink MM, Hutter I, Bailey A. Qualitative research methods SAGE; 2011:304.

25. Mills J, Bonner A, Francis K. The development of constructivist grounded theory. Int J Qual Methods [Internet]. 2006;5:25-35. [cited 2020 Dec 9]Available from. http://journals.sagepub. $\mathrm{com} /$ doi/10.1177/160940690600500103.

26. Domínguez LC, Dolmans D, de Grave W, Donkers J, Sanabria A, Stassen L. Transformational leadership encourages residents' job crafting in surgical training: A mixed-methods study of residents' perceptions. Submitted.

27. Avolio B. Full range leadership. Full Range Leadership Development SAGE Publications, Inc.; 2014:49-74.

28. Corbin J, Strauss A. Techniques and Procedures for Developing Grounded Theory. 3rd ed. Basics of qualitative research (3rd ed): techniques and procedures for developing grounded theory basics of qualitative research. SAGE Publications, Inc; 2012.

29. Varpio L, Ajjawi R, Monrouxe LV, O’Brien BC, Rees CE. Shedding the cobra effect: Problematising thematic emergence, triangulation, saturation and member checking. Med Educ. 2017;51:40-50

30. van Nes F, Abma T, Jonsson H, Deeg D. Language differences in qualitative research: is meaning lost in translation? Eur J Ageing [Internet]. 2010;7:313-316. [cited 2018 Dec 13]Available from. http://www.ncbi.nlm.nih.gov/pubmed/21212820

31. Santos HPO, Black AM, Sandelowski M. Timing of translation in cross-language qualitative research. Qual Health Res [Internet]. 2014;25:134-144 Available from. doi:10.1177/1049732314549603.

32. Tong A, Sainsbury P, Craig J. Consolidated criteria for reporting qualitative research (COREQ): a 32-item checklist for interviews and focus groups. Int J Qual Heal care J Int Soc Qual Heal Care [Internet]. 2007;19:349-357. [cited 2019 Jul 16]Available from. https://academic.oup.com/intqhe/ article-lookup/doi/10.1093/intqhc/mzm042

33. Thomson NB, Rawson JV, Slade CP, Bledsoe M. transformation and transformational leadership: a review of the current and relevant literature for academic radiologists. vol. 23, academic radiology Elsevier USA; 2016:592-599.

34. Geerts JM, Goodall AH, Agius S. Evidence-based leadership development for physicians: A systematic literature review. Vol. 246, Social Science and Medicine. Elsevier Ltd; 2020.

35. Wang H-J, Demerouti E, Le Blanc P. Transformational leadership, adaptability, and job crafting: The moderating role of organizational identification. J Vocat Behav [Internet]. 2017;100:185-195. [cited 2019 Aug 28]Available from. https: //linkinghub.elsevier.com/retrieve/pii/S0001879117300271.
36. Hetland J, Hetland H, Bakker AB, Demerouti E. Daily transformational leadership and employee job crafting: The role of promotion focus. Eur Manag J [Internet]. 2018;36:746-756. [cited 2019 Aug 28]Available from. https: //linkinghub.elsevier.com/retrieve/pii/S0263237318300021

37. Miglianico M, Dubreuil P, Miquelon P, Bakker AB, Martin-Krumm C. Strength use in the workplace: a literature review. Vol. 21 Journal of Happiness Studies. Springer; 2020:737-764.

38. Sharp G, Bourke L, Rickard MJFX. Review of emotional intelligence in health care: an introduction to emotional intelligence for surgeons [Internet]. ANZ Journal of Surgery. Blackwell Publishing; 2020 [cited 2020 Apr 20]. Available from http://www.ncbi.nlm.nih.gov/pubmed/31965690

39. Barzallo Salazar MJ, Minkoff H, Bayya J, Gillett B, Onoriode H, Weedon J, et al. Influence of surgeon behavior on trainee willingness to speak up: A randomized controlled trial. Journal of the American College of Surgeons [Internet] Elsevier Inc.; 2014:1001-1007.

40. Salles A, Wright RC, Milam L, Panni RZ, Liebert CA, Lau JN, et al. Social belonging as a predictor of surgical resident well-being and attrition. J Surg Educ. 2019;76:370-377 1.

41. Hayek S, Buonpane C, Hummel C, Lane S, Ellison H, Young K, et al. How applicants to general surgery residency define resilience. J Surg Educ [Internet]. 2020;77. [cited 2020 Jun 22]Available from. https://pubmed.ncbi.nlm.nih.gov/ 32192887/

42. Cope A, Bezemer J, Mavroveli S, Kneebone R. What attitudes and values are incorporated into self as part of professional identity construction when becoming a surgeon?. Academic Medicine [Internet]. Lippincott Williams and Wilkins; 2017:544-549.

43. Solberg E, Wong SI When proactivity requires adaptivity across levels. Leadersh Q; 2016:713-725.

44. Luu TT Ind Mark Manag; 2020:89-104.

45. Thun S, Bakker AB The role of employee optimism. Stress Health [Internet]; 2018:573-581.

46. Xin X, Cai W, Zhou W, Baroudi SE, Khapova SN. How can job crafting be reproduced? Examining the trickle-down effect of job crafting from leaders to employees. Int J Environ Res Public Health. 2020;17(3):894-899. doi:10.3390/ijerph17030894.

47. Esteves T, Pereira Lopes M. Leading to crafting: the relation between leadership perception and nurses' job crafting. West J Nurs Res [Internet]. 2017;39:763-783. Jun 1 [cited 2020 Apr 21]Available from. http://www.ncbi.nlm.nih.gov/pubmed/ 27432346

48. Rosengart TK, Mason MC, LeMaire SA, Brandt ML, Coselli JS, Curley SA, et al. The seven attributes of the academic surgeon: Critical aspects of the archetype and contributions to the surgical community. Am J Surg [Internet]. 2017;214:165-179. [cited 2020 Apr 20]Available from. http://www.ncbi.nlm.nih.gov/pubmed/28284432

49. Swendiman RA, Marcaccio CL, Han J, Hoffman DI, Weiner TM, Nance ML, et al. Attitudes and habits of highly humanistic surgeons: a single-institution, mixed-methods study. Acad Med [Internet]. 2019;94:1027-1032. [cited 2020 Apr 20]Available from. http://www.ncbi.nlm.nih.gov/pubmed/30844930

50. Dickinson KJ, Bass BL, Pei KY. What embodies an effective surgical educator? A grounded theory analysis of resident opinion. In: Surgery (United States) [Internet]. Mosby Inc.; 2020 [cited 2020 Aug 7]. Available from: http: //www.surgjournal.com/article/S0039606020302701/fulltext

51. McIlhenny C, Kurashima Y, Chan C, Hirano S, Domínguez-Rosado I, Stefanidis D. General surgery education across three continents. Am J Surg [Internet]. 2018;215:209-213. [cited 2020 Feb 29]Available from. http://www.ncbi.nlm.nih.gov/pubmed/29246406

52. JR Jr Wright, Schachar NS. Necessity is the mother of invention: William Stewart Halsted's addiction and its 
influence on the development of residency training in North America. Can J Surg [Internet]. 2020;63. [cited 2020 Feb 29]E13-9Available from.

http://www.ncbi.nlm.nih.gov/pubmed/31944636.

53. Kotsis SV, Chung KC. Application of the "see one, do one, teach one" concept in surgical training. Plast Reconstr Surg [Internet]. 2013;131:1194-1201. [cited 2020 Mar 3]Available from. http://www.ncbi.nlm.nih.gov/pubmed/23629100 .
54. Norrell K, Marasigan J, Bogener J. New paradigms in post-graduate surgical education. Mo Med [Internet]. 2017;114:278-282. [cited 2020 Apr 21] Available from. http://www.ncbi.nlm.nih.gov/pubmed/30228611 .

55. Ten Cate O, Chen HC, Hoff RG, Peters H, Bok H, Van Der Schaaf M. Curriculum development for the workplace using Entrustable Professional Activities (EPAs): AMEE Guide No. 99. Med Teach. 2015;37:983-1002. 